\title{
BEBERAPA ASPEK BIOLOGI IKAN SWANGGI (Priacanthus tayenus) YANG DIDARATKAN DI PPP TAWANG KABUPATEN KENDAL
}

\author{
Some Biological Aspects of Swanggi Fish (Priacanthus tayenus) which are landed \\ in Tawang Fishing Port of Kendal Regency
}

Arinta Maulidina Agustiari, Suradi Wijaya Saputra*) dan Anhar Solichin

Program Studi Manajemen Sumberdaya Perairan, Departemen Sumberdaya Akuatik

Fakultas Perikanan dan Ilmu Kelautan, Universitas Diponegoro

Jl. Prof. Soedarto, SH, Tembalang, Semarang, Jawa Tengah - 50275, Telp/Fax. +6224 7474698

Email : arintamaulidina@yahoo.co.id

\begin{abstract}
ABSTRAK
Pelabuhan Perikanan Pantai Tawang merupakan pelabuhan yang cukup besar di Kabupaten Kendal. Salah satu hasil tangkapan yang didaratkan yaitu ikan Swanggi (Priacanthus tayenus) merupakan jenis ikan demersal dengan karakteristik khusus berwarna merah muda, memiliki mata besar dan pada sirip perutnya terdapat bintik berwarna kehitam-hitaman. Tujuan penelitian ini adalah mengetahui aspek biologi ikan Swanggi meliputi struktur ukuran, hubungan panjang berat, faktor kondisi $(\mathrm{Kn})$, ukuran pertama kali tertangkap ( $\left.\mathrm{Lc}_{50 \%}\right)$, ukuran pertama kali matang gonad ( $\mathrm{Lm}_{50 \%}$ ), tingkat kematangan gonad (TKG), indeks kematangan gonad (IKG), diameter telur, fekunditas dan upaya pengelolaan sumberdaya ikan Swanggi (Priacanthus tayenus). Penelitian dilaksanakan pada bulan Maret - April 2016. Metode penelitian adalah survei. Pengambilan sampel menggunakan metode random sampling atau acak. Hasil penelitian dilakukan pada ikan Swanggi sebanyak 625 ekor, pertumbuhan ikan Swanggi bersifat allometrik negatif dengan persamaan $\mathrm{W}=0,00045 \mathrm{~L}^{2,30701}$. Panjang ikan yang tertangkap selama penelitian berkisar antara $105-324 \mathrm{~mm}$ dan berat berkisar antara 22 - 205,2 gram. Nilai faktor kondisi adalah 1,106. Nilai Ukuran pertama kali tertangkap $\left(\mathrm{Lc}_{50 \%}\right)$ adalah $152 \mathrm{~mm}$.Ukuran pertama kali matang gonad $\left(\mathrm{Lm}_{50 \%}\right)$ yaitu $153 \mathrm{~mm}$. Ikan Swanggi jantan maupun betina sebagian besar belum matang gonad. Nilai TKG yang semakin tinggi akan diikuti dengan tingginya nilai IKG dan diameter telur juga semakin besar. Fekunditas tertinggi sebesar 245303 butir. Hubungan fekunditas terhadap panjang dan berat ikan Swanggi menunjukkan koefisien korelasi lemah.
\end{abstract}

Kata Kunci : Ikan Swanggi (Priacanthus tayenus), Aspek Biologi, PPP Tawang

\section{ABSTRACT}

Tawang Coastal Fishing Port is a huge port in Kendal Regency. One of its hauls which was landed is Red Bigeye fish (Priacanthus tayenus). Which include in demersal fish with special characters; they have pink color, big eyes, and black spots around their pelvic fins. The purpose of this research is to find out the biological aspect of Red Bigeye fish from several aspects, i.e. size of the structure, relation of length and weight, the conditions factor (Kn), the size of the first caught (Lc $50 \%)$, the first time size of gonad maturity $\left(L m_{50 \%}\right)$, gonad maturity level (TKG), index of gonad maturity (IKG), diameter of egg, fecundity, and management effort of Red Bigeye fish (Priacanthus tayenus) resources. The research was conducted in March - April 2016. The method used in this research is survey. In taking sample, this research use random sampling method. The result was done on 625 Swanggi fish. The growth of Red Bigeye fish is negative allometric with equation $W=0,00045 L^{2,30701}$. The length of caught fish for the research are around $105-324$ $\mathrm{mm}$ and weight around $22-205,2$ gram. The value of condition factor is 1,106. The value of first time caught is 152 $\mathrm{mm}$. The value of first time mature gonad ( $\mathrm{Lm}_{50 \%}$ ) is $153 \mathrm{~mm}$. Most male and female Red Bigeye fish are immature gonads. The higher TKG value will be followed by the higher IKG and egg diameter will be bigger. The highest fecundity is 245303 grain. The fecundity relation toward the weight of Red Bigeye fish shows weak correlation coefficient.

Keywords : Swanggi Fish (Priacanthus tayenus), Biological Aspect, Tawang Coastal Fishing Port

*) Penulis Penanggungjawab

1. PENDAHULUAN

Pelabuhan Perikanan Pantai Tawang merupakan pelabuhan yang cukup besar di Kabupaten Kendal terletak di Desa Gempolsewu, Kecamatan Rowosari. Salah satu hasil tangkapan yang didaratkan yaitu Ikan Swanggi (Priacanthus 
tayenus) merupakan salah satu ikan yang cukup banyak dikonsumsi masyarakat Kendal karena harganya yang ekonomis dengan karakteristik khusus berwarna merah muda, memiliki mata besar, pada sirip perutnya terdapat bintik berwarna kehitam-hitaman dan termasuk jenis ikan demersal. Penangkapan ikan Swanggi dengan menggunakan jaring Arad yang memiliki mesh size 1 inchi, apabila dilakukan terus menerus memungkinkan perkembangan stok ikan terhambat dan mengancam potensi dari ikan Swanggi. Permasalahan tersebut menjadikan pentingnya dilakukan penelitian agar kondisi sumberdaya ikan Swanggi dapat terjaga dengan baik. Berdasarkan permasalahan tersebut perlu diteliti data aspek biologi antara lain struktur ukuran, panjang dan berat, faktor kondisi, ukuran pertama kali tertangkap, ukuran pertama kali matang gonad, tingkat kematangan gonad, indeks kematangan gonad, fekunditas, dan diameter telur. Penelitian ini penting bagi perkembangan pemanfaatan dan pengelolaan sumberdaya perikanan tangkap yang lestari dan berkelanjutan.

Tujuan dari penelitian adalah mengetahui aspek biologi ikan Swanggi (Priacanthus tayenus) yang meliputi: aspek pertumbuhan (struktur ukuran, hubungan panjang berat, ukuran pertama kali tertangkap, faktor kondisi, ukuran pertama kali matang gonad) dan aspek reproduksi (tingkat kematangan gonad, indeks kematangan gonad, fekunditas, diameter telur) serta mengetahui upaya pengelolaan untuk kelangsungan stok sumberdaya ikan Swanggi.

\section{MATERI DAN METODE Materi Penelitian}

Alat yang digunakan dalam penelitian ini adalah timbangan digital berkapasitas 450 gram dengan ketelitian 0,1 gram (mengukur berat ikan) dan timbangan digital berkapasitas 200 gram dengan ketelitian 0,01 gram (mengukur berat gonad ikan), penggaris dengan ketelitian $1 \mathrm{~mm}$ untuk mengukur panjang ikan, mikroskop untuk pengamatan fekunditas dan diameter telur ikan, gelas beaker $50 \mathrm{ml}$ sebagai wadah pengenceran gonad, alat sectio untuk membedah ikan, pipet tetes untuk mengambil telur yang diencerkan, sedgewick rafter untuk mencacah telur ikan, hand counter untuk menghitung telur ikan. Alat tambahan lain yaitu kamera berfungsi sebagai alat dokumentasi.

Bahan yang digunakan dalam penelitian ini adalah aquades untuk mengencerkan telur dan alkohol $70 \%$ untuk mengawetkan gonad. Es batu untuk pengawetan ikan dan box sterofom sebagai wadah ikan.

\section{Metode Penelitian}

\section{Metode Sampling}

\section{a. Metode Penentuan Kapal}

Sampel kapal adalah kapal Arad yang mendaratkan hasil tangkapan di PPP Tawang, Kendal. Sampel mengikuti prosedur yang dikemukakan oleh Sadhotomo dan Poiter (1991) dalam Saputra (2009) seperti berikut :

1. Jika kapal yang mendarat kurang dari 5 kapal dipilih satu kapal yaitu kapal no 1;

2. Jika kapal yang datang 5-10 kapal, maka dipilih 2 kapal sebagai kapal sampel. Kapal sampel pertama adalah kapal nomor urut 1 dari daftar nomor urut kapal. Apabila kedua daerah penangkapannya sama dengan nomor 1, maka kapal sampel kedua adalah kapal nomor berikutnya dengan daerah penangkapan yang berbeda dengan kapal nomor 1 , dan seterusnya jumlah kapal mengikuti kelipatan 5.

\section{b. Metode Pengambilan Sampel Ikan}

Pengambilan sampel ikan dilakukan selama dua bulan yaitu Maret dan April 2016. Pengambilan ikan sampel untuk data panjang dan berat dilakukan setiap hari. Hasil tangkapan ikan Swanggi diambil 10\% dari total hasil tangkapan, sebagai sumber data panjang dan berat ikan, data fekunditas, Tingkat Kematangan Gonad (TKG) dan diameter telur. Ikan contoh yang diambil menggunakan metode penarikan contoh acak (random sampling). Sampel ikan tiap kapal diambil 10\% dari jumlah ikan tersebut (Sugiharto, 2009 dalam Rahman et al., 2013).

\section{Data Primer}

Data primer yang diambil data panjang dan berat, tingkat kematangan gonad, fekunditas, dan diameter telur diperoleh dari:

1. Panjang ikan, dilakukan dengan mengukur panjang total dari ikan Swanggi, yaitu mulai dari mulut sampai dengan ujung ekor dan mengunakan penggaris dengan ketelitian $1 \mathrm{~mm}$;

2. Berat ikan, dilakukan dengan menimbang menggunakan timbangan digital dengan ketelitian 0,1 gram;

3. Tingkat Kematangan Gonad diperoleh dengan pengamatan secara morfologi gonad dengan mengambil mengukur bentuk gonad, berat gonad, warna gonad, perkembangan isi gonad. Penimbangan gonad menggunakan timbangan elektrik dengan ketelitian 0,01 gram dan menggunakan kriteria tingkat kematangan gonad Holden dan Raitt (1974) dalam Diana (2007);

4. Data fekunditas diperoleh dengan menghitung telur pada gonad TKG III dan IV. Perhitungan fekunditas dilakukan di Laboratorium Manajemen Sumberdaya Ikan dan Lingkungan, Fakultas Perikanan dan Ilmu Kelautan Universitas Diponegoro Semarang. Perhitungan fekunditas dilakukan dengan membagi gonad menjadi lima bagian. Mengambil bagian ujung, tengah, dan pangkal gonad sehingga diharapkan seluruh bagian terwakili. Sampel gonad ditimbang, kemudian diencerkan menggunakan $100 \mathrm{ml}$ air. Setelah telur tidak ada lagi yang menggerombol, perhitungan telur dapat dilakukan. Perhitungan dilakukan dengan meneteskan dalam sedgewick rafter dan mengamati di bawah mikroskop. Pengamatan dilakukan sebanyak 3 kali pengulangan untuk setiap sampelnya; dan

5. Data diameter telur dilakukan dengan pengamatan dibawah mikroskop dengan alat bantu pengukuran micrometer okuler dengan perbesaran 100 kali yang sudah dikalibrasi. Pengukuran diameter telur dilakukan dengan mengamati butir telur yang diambil dari 3 bagian, yaitu : pangkal, tengah, dan ujung. Menurut Assidiqqi et al., (2011), Perhitungan 
kalibrasi yang sudah dilakukan untuk diketahui satu satuan panjang pada skala mikrometer okuler adalah Skala Objektif $=60$, Skala Okuler $=60$, perbesaran $100 \mathrm{kali}=0,01 \times 60: 60=0,01 \mathrm{~mm}$. Menggunakan rumus :

$$
\begin{aligned}
\begin{array}{c}
1 \text { skala okuler } \\
(\mathrm{O} . \mathrm{D}=\text { Okuler Division })
\end{array} & \frac{\text { Jarak yang diketahui antara 2 garis pada mik. Objektif }}{\text { Jarak skala pada mikrometer okuler }} \\
= & 0,01 \times \frac{\text { Skala Objektif }}{\text { Skala Okuler }}(\mathrm{mm}) \\
= & 10 \times \frac{\text { Skala Objektif }}{\text { Skala Okuler }} \quad(\mu \mathrm{m})
\end{aligned}
$$

\section{Analisis Data}

Aspek Pertumbuhan

a. Hubungan Panjang Berat

Data panjang berat yang telah diperoleh kemudian dianalisis dengan alat bantu hitung yaitu Microsoft excel. Hubungan panjang bobot ikan Swanggi dianalisis menggunakan persamaan yang dikemukakan oleh Effendie (2002), $\mathrm{W}=\mathrm{aL}^{\mathrm{b}}$ kemudian ditransformasikan kedalam bentuk logaritma, sehingga membentuk persamaan linier sebagai berikut:

Keterangan :

$$
\log \mathrm{W}=\log \mathrm{a}+\mathrm{b} \log \mathrm{L}
$$

$\mathrm{W}=$ berat $(\mathrm{g}) \quad, \mathrm{L}=$ panjang total $(\mathrm{mm}), \mathrm{a}=$ intercept, $\mathrm{b}=$ slope

Untuk menguji nilai $b=3$ atau $b \neq 3$ dilakukan uji $t$ (uji parsial), dengan rumus Walpole (1992) dalam Simanjuntak (2010) :

$$
\mathrm{t}_{\text {hit }}=\left|\frac{\mathrm{b}-3}{\mathrm{SEb}}\right|
$$

$t_{\text {hit }}$ adalah $t$ hitung, $b$ adalah intercept dan SEb adalah standar error dari nilai b. Hipotesis :

Ho $: b=3$, hubungan panjang dengan berat adalah isometrik

$\mathrm{H}_{1}: \mathrm{b} \neq 3$, hubungan panjang dengan berat adalah allometrik, yaitu:

Allometrik positif jika $\mathrm{b}>3$ (pertambahan berat lebih cepat daripada pertambahan panjang) dan Allometrik negatif jika $b<3$ (pertambahan panjang lebih cepat daripada pertambahan berat).

Selanjutnya $t_{\text {hit }}$ yang didapat dibandingkan dengan $t_{\text {tabel }}$ pada selang kepercayaan $95 \%$. Jika $t_{\text {hit }}>t_{\text {tabel }}$ maka Ho ditolak, dan sebaliknya jika $\mathrm{t}_{\text {hit }}<\mathrm{t}_{\text {tabel }}$ maka Ho diterima.

\section{b. Faktor Kondisi}

Menurut Effendie (2002), faktor kondisi (K) dapat ditentukan berdasarkan panjang dan berat ikan contoh. Rumus yang digunakan untuk mengetahui faktor kondisi dibedakan berdasarkan pola pertumbuhan. Pada ikan yang memiliki pola pertumbuhan allometrik $(b \neq 3)$, maka rumus yang digunakan adalah:

$$
\mathrm{K}=\frac{\mathrm{W}}{\mathrm{aL}^{\mathrm{b}}}
$$

Keterangan :

$\mathrm{K}=$ faktor kondisi

$\mathrm{W}=$ berat rata-rata ikan satu kelas $(\mathrm{g})$

\section{c. Ukuran pertama kali ikan tertangkap ( $\left.\mathrm{Lc}_{50 \%}\right)$}

$\mathrm{L} \quad=$ panjang rata-rata ikan satu kelas $(\mathrm{mm})$

Ukuran pertama kali ikan tertangkap diperoleh dengan mencari nilai ukuran tengah ikan yang tertangkap.

Metode penentuan ukuran ikan pertama kali tertangkap dilakukan dengan cara sebagai berikut :

1. Membuat interval panjang ikan, nilai tengah panjang dan menghitung frekuensi setiap kelas panjang;

2. Menghitung persentase kumulatif masing-masing kelas panjang; dan

3. Nilai ukuran pertama kali ikan tertangkap $\left(\mathrm{Lc}_{50 \%}\right)$ diperoleh dengan memplotkan persentase kumulatif ikan yang tertangkap dengan nilai tengah panjang ikan.

\section{d. Ukuran pertama kali ikan matang gonad (Lm50\%)}

Metode untuk mengetahui ukuran pertama kali matang gonad adalah dengan memplotkan persentase kumulatif ikan matang gonad dengan nilai tengah panjang ikan dilakukan dengan cara sebagai berikut :

1. Membuat interval panjang ikan, nilai tengah panjang dan menghitung frekuensi setiap kelas panjang;

2. Menghitung jumlah ikan yang matang gonad sesuai interval panjang ikan;

3. Menghitung persentase kumulatif masing-masing kelas panjang; dan

4. Nilai ukuran pertama kali matang gonad $\left(\mathrm{Lm}_{50 \%}\right)$ diperoleh dengan memplotkan persentase kumulatif ikan yang tertangkap dengan nilai tengah panjang ikan. 


\section{Aspek Reproduksi}

a. Tingkat Kematangan Gonad

Penentuan TKG dilakukan melalui pengamatan struktur morfologis (visual) dengan menggunakan ciri TKG yang dikemukakan oleh Holden dan Raitt (1974) dalam Diana (2007). Dasar yang dipakai untuk menentukan TKG adalah bentuk, warna gonad, dan perkembangan isi gonad yang tampak. Tingkat kematangan gonad ikan menurut klasifikasi Holden dan Raitt (1974) dalam Diana (2007) disajikan pada Tabel 1.

Tabel 1 . Tingkat Kematangan Gonad Menurut Holden dan Raitt (1974) dalam Diana (2007)

\begin{tabular}{|c|c|c|}
\hline Tingkat & Kategori & Keterangan \\
\hline $\mathrm{I}$ & Immature (belum matang) & $\begin{array}{l}\text { Ovarium dan testis sekitar } 1 / 3 \text { panjang rongga perut. Ovarium } \\
\text { berwarna merah jambu dan transparan. Testis berwarna } \\
\text { keputihan, telur tidak bisa dilihat dengan mata telanjang. }\end{array}$ \\
\hline II & Developing (Perkembangan) & $\begin{array}{l}\text { Panjang ovarium dan testis sekitar } 1 / 2 \text { rongga perut. Ovarium } \\
\text { transparan dan berwarna kemerah merahan, telur tidak dapat } \\
\text { dilihat dengan mata telanjang. }\end{array}$ \\
\hline III & Ripening (Pematangan) & $\begin{array}{l}\text { Ovarium dan testis sekitar } 2 / 3 \text { panjang rongga perut. Ovarium } \\
\text { merah jambu kekuningan dan terlihat butiran kecil. Testis putih } \\
\text { krem, telur transparan dan dapat diamati dengan mata telanjang. }\end{array}$ \\
\hline IV & Ripe/Fully Mature (matang) & $\begin{array}{l}\text { Ovarium dan testis sekitar } 2 / 3 \text { sampai memenuhi rongga perut. } \\
\text { Ovarium cokelat kemerahan, banyak diliputi pembuluh darah. } \\
\text { Telur dapat diamati dengan mata telanjang. }\end{array}$ \\
\hline V & Spent (pasca memijah) & $\begin{array}{l}\text { Ovarium dan testis berkurang sampai } 1 / 2 \text { panjang rongga perut. } \\
\text { Dinding mungkin masih terdapat sisa telur matang . testis } \\
\text { lembek dan pendek. }\end{array}$ \\
\hline
\end{tabular}

\section{b. Indeks Kematangan Gonad}

Indeks kematangan gonad (IKG) ditentukan sebagaimana cara yang dilakukan oleh Johnson (1971) dalam Effendie (2002) dengan rumus:

$$
\mathrm{IKG}=\underline{\mathrm{BT}} \times 100 \%
$$

Keterangan:

$\mathrm{IKG}=$ indeks kematangan gonad, $\mathrm{BG}=$ berat $\operatorname{gonad}(\mathrm{gr}), \mathrm{BT}=$ berat tubuh $(\mathrm{gr})$

c. Fekunditas

Fekunditas ikan Swanggi dihitung pada ikan yang mempunyai TKG III dan IV dan dihubungkan dengan panjang dan berat ikan (Effendie, 2002). Fekunditas adalah jumlah telur masak sebelum dikeluarkan pada saat ikan memijah. Perhitungan telur ikan dilakukan dengan menggunakan metode gabungan. Menurut Effendie (2002), fekunditas dapat dihitung menggunakan rumus sebagai berikut :

Keterangan:

$$
\mathrm{F}=\frac{(\mathrm{G} \times \mathrm{V} \times \mathrm{X})}{\mathrm{Q}}
$$

$\mathrm{F}=$ fekunditas (butir telur) $\quad \mathrm{G}=$ berat gonad total (gram)

$\mathrm{V}=$ volume pengenceran $(\mathrm{ml}) \quad \mathrm{Q}=$ berat telur contoh (gram)

$\mathrm{X}=$ jumlah telur yang ada dalam $1 \mathrm{cc}$ (butir)

Fekunditas sering dihubungkan dengan panjang dan berat, menurut Bagenal, 1978 dalam Iswara (2014) hubungan fekunditas dengan panjang dan berat digambarkan dengan persamaan:

Keterangan :

$$
\begin{aligned}
& \mathrm{F}=\mathrm{a} . \mathrm{L}^{\mathrm{b}} \\
& \mathrm{F}=\mathrm{a} \cdot \mathrm{W}^{\mathrm{b}}
\end{aligned}
$$

$\mathrm{F}=$ fekunditas

$\mathrm{b}=$ eksponen regresi

$\mathrm{a}=$ sumbu regresi

Menurut Sugiarto (1992) dalam Prayudha (2014), hubungan koefisien korelasi secara sistematis pada hubungan panjang dan berat ikan terhadap fekunditas adalah sebagai berkut:

1. $\mathrm{r}=0$ berarti tidak ada korelasi;

2. $r>0-0,5$ berarti korelasi lemah;

3. $r>0,5-0,8$ berarti korelasi sedang;

4. $r>0,8-1$ berarti korelasi kuat; dan

5. $r=1$ berarti korelasi sempurna. 
3.

HASIL DAN PEMBAHASAN

HASIL

Aspek Pertumbuhan

a. Struktur ikan Swanggi (Priacanthus tayenus)

Hasil sampling diperoleh 625 ekor dengan kisaran panjang ikan Swanggi berkisar antara $105-324 \mathrm{~mm}$ dan berat berkisar antara 22 - 205,2 gram. Histogram struktur ukuran ikan Swanggi dapat dilihat pada Gambar 1.

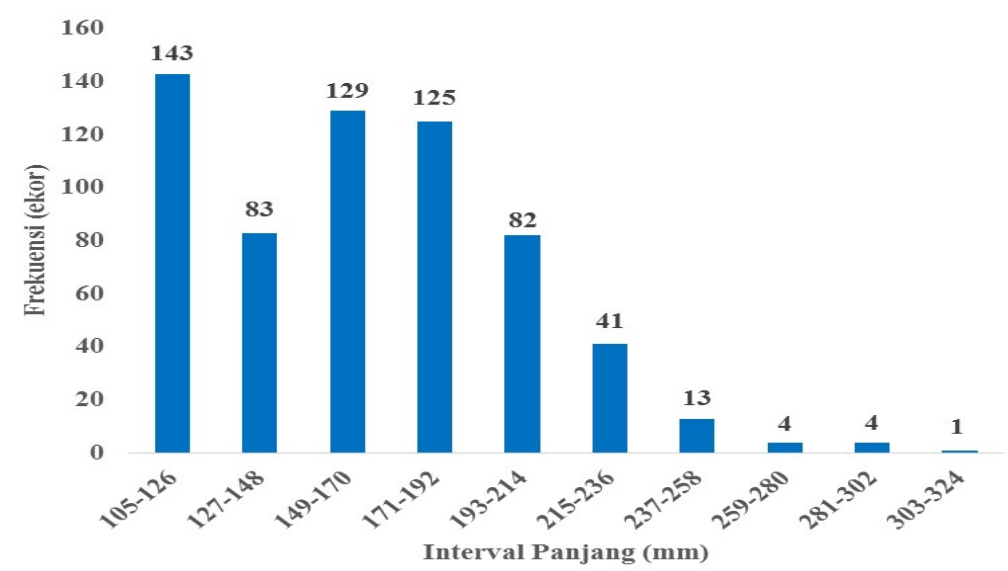

Gambar 1. Histogram struktur ukuran ikan Swanggi (Priacanthus tayenus)

Histogram tersebut menunjukkan bahwa ikan dengan kisaran panjang $105-126 \mathrm{~mm}$ merupakan ukuran yang paling banyak tertangkap selama penelitian dengan jumlah 143 ekor. Sedangkan ukuran ikan dengan kisaran panjang $303-324 \mathrm{~mm}$ merupakan ukuran paling sedikit tertangkap yaitu sebanyak 1 ekor.

b. Hubungan Panjang Berat

Panjang ikan Swanggi berkisar berkisar antara $105-324 \mathrm{~mm}$ dan berat berkisar antara 22 - 205,2 gram. Hubungan panjang berat ikan Swanggi yang tertangkap dengan alat tangkap Arad yang dapat dilihat pada Gambar 2 .

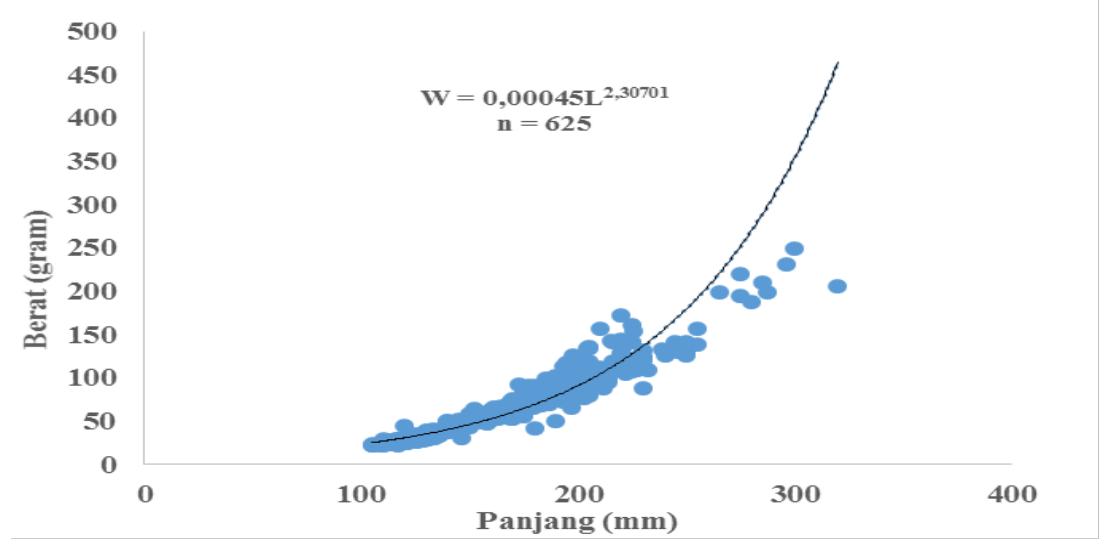

Gambar 2. Hubungan panjang berat ikan Swanggi

Berdasarkan analisis hubungan panjang berat diperoleh persamaan $\mathrm{W}=0,00045 \mathrm{~L}^{2,30701}$, dengan nilai a sebesar 0,00045 dan nilai $\mathrm{b}<3$, yaitu sebesar 2,30701. Modus panjang sebesar ikan Swanggi $120 \mathrm{~mm}$. Nilai t hitung sebesar 37,4 dan nilai $t$ tabel sebesar 1,96 sehingga $t$ hitung $>t$ tabel maka tolak Ho. Hal ini menunjukkan bahwa pertumbuhan ikan Swanggi bersifat allometrik negatif.

\section{c. Faktor Kondisi}

Faktor kondisi merupakan parameter kemontokan ikan dan dinyatakan dalam angka. Hasil analisa regresi yang diperoleh dari hasil pengamatan panjang dan berat di lapangan diperoleh nilai a sebesar 0,00045 dan nilai $\mathrm{b}$ sebear 2,30701 . Hasil perhitungan statistik deskriptif diperoleh panjang rata-rata sebesar $165,15 \mathrm{~mm}$ dan berat sebesar 65,12 gram. Berdasarkan hasil tersebut nilai faktor kondisi (Kn) ikan Swanggi yaitu 1,106.

d. Ukuran pertama kali ikan tertangkap (Les0\%)

Ukuran pertama kali tertangkap dihitung dengan tujuan untuk dijadikan dasar dalam pengaturan alat tangkap yang digunakan demi menjaga kelestarian sumberdaya ikan. Hasil perhitungan ukuran pertama kali tertangkap tersaji pada Gambar 3. 


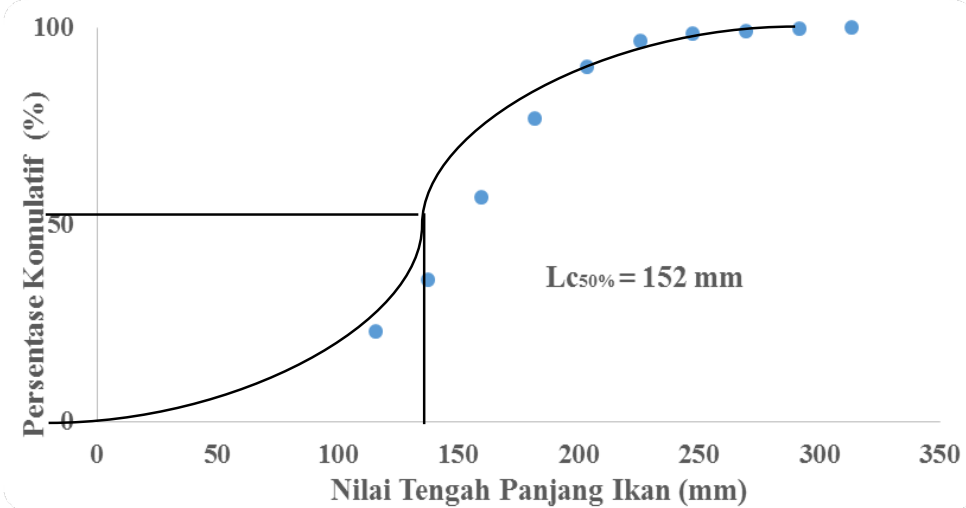

Gambar 3 . Grafik ukuran pertama kali tertangkap ( $\left.\mathrm{Lc}_{50 \%}\right)$ ikan Swanggi

Ukuran pertama kali tertangkap ikan Swanggi ( $\operatorname{Lc}_{50 \%}$ ) adalah $152 \mathrm{~mm}$. Nilai $\mathrm{L}_{\infty}$ sebesar 336,84 $\mathrm{mm}$ dan $1 / 2 \mathrm{~L}_{\infty}$ sebesar 168,42 mm yang berarti bahwa ukuran ikan yang tertangkap masih kecil dan belum layak ditangkap, karena nilai $\mathrm{Lc}_{50 \%}<1 / 2 \mathrm{~L}_{\infty}$. Nilai $\mathrm{L}_{\infty}$ diperoleh dari rumus ukuran maksimal ikan Swanggi dibagi 0,95. $\mathrm{Lc}_{50 \%}=152 \mathrm{~mm}$.

\section{e. Ukuran pertama kali matang gonad ( $\left.\mathbf{L m}_{50 \%}\right)$}

Ukuran pertama kali matang gonad ikan Swanggi dihitung dengan tujuan untuk mengetahui pada ukuran berapa ikan Swanggi tersebut pertama kali matang gonad. Ukuran $\mathrm{Lm}_{50 \%}$ sangat penting dan dapat dijadikan acuan dalam pengelolaa. Hal tersebut dilakukan untuk tetap menjaga kelestarian sumberdaya ikan tersebut. Hasil perhitungan ukuran pertama kali matang gonad ( $\left.\mathrm{Lm}_{50 \%}\right)$ tersaji pada Gambar 4.

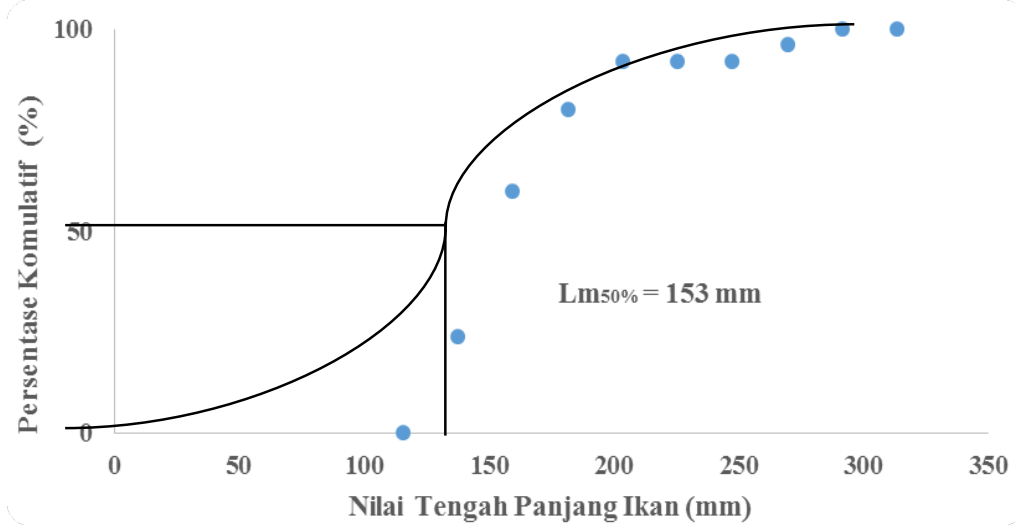

Gambar 4. Grafik ukuran pertama kali matang gonad (Lm50\%) ikan Swanggi

Berdasarkan grafik diatas dapat dilihat bahwa ikan Swanggi pertama kali matang gonad ukuran $153 \mathrm{~mm}$.

\section{Aspek Reproduksi ikan Swanggi}

\section{a. Tingkat Kematangan Gonad}

Penentuan tingkat kematangan gonad menggunakan metode Menurut Holden dan Raitt (1974) dalam Diana (2007). Sampel ikan yang diamati untuk TKG selama penelitian berjumlah 100 ekor. Sampel ikan Swanggi jantan sebanyak 42 ekor dan ikan Swanggi betina sebanyak 58 ekor. Tingkat kematangan gonad ikan Swanggi jantan dapat dilihat pada Gambar 5.

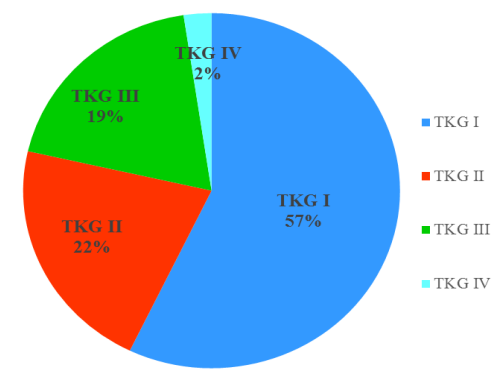

Gambar 5. Persentase Tingkat Kematangan Gonad ikan Swanggi Jantan

Berdasarkan hasil penelitian menunjukkan bahwa TKG I merupakan persentase terbesar yaitu $57 \%$. TKG IV merupakan persentase terkecil yaitu $2 \%$. TKG I dan II merupakan gonad yang belum matang sedangkan TKG III dan IV merupakan gonad yang sudah matang. Tingkat kematangan gonad pada ikan Swanggi betina dapat dilihat pada Gambar 6 . 


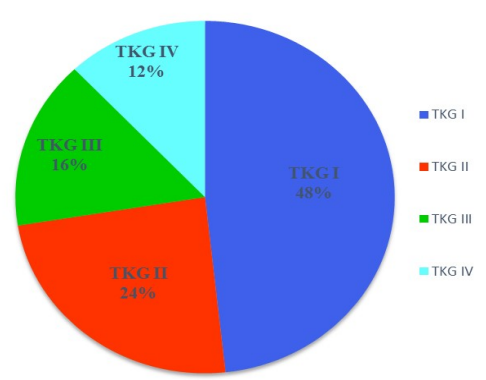

Gambar 6. Persentase Tingkat Kematangan Gonad ikan Swanggi Betina

Berdasarkan hasil penelitian menunjukkan bahwa TKG I merupakan persentase terbesar yaitu $48 \%$ sedangkan TKG IV merupakan persentase terkecil yaitu $12 \%$. TKG I dan II merupakan gonad yang belum matang sedangkan TKG III dan IV merupakan gonad yang sudah matang.

\section{b. Indeks Kematangan Gonad}

Hasil perhitungan Indeks Kematangan Gonad didapatkan nilai terendah pada ikan Swanggi jantan sebesar $0,018 \%$ dengan panjang $154 \mathrm{~mm}$ dan nilai IKG tertinggi sebesar 0,732\% dengan panjang $170 \mathrm{~mm}$. Sedangkan nilai IKG terendah pada ikan Swanggi betina sebesar 0,034\% dengan panjang $157 \mathrm{~mm}$ dan nilai IKG tertinggi sebesar 3,286 \% dengan panjang $198 \mathrm{~mm}$. Hasil perhitungan indeks kematangan gonad tersaji dalam Tabel 2.

Tabel 2. Indeks Kematangan Gonad ikan Swanggi Selama Penelitian

\begin{tabular}{|c|c|c|c|c|}
\hline \multirow{2}{*}{ TKG } & \multicolumn{2}{|c|}{ IKG } & \multicolumn{2}{|c|}{ Rata-rata } \\
\hline & Jantan & Betina & Jantan & Betina \\
\hline I & $0.018-0.117$ & $0.034-0.435$ & 0.065 & 0.377 \\
\hline II & $0.052-0.227$ & $0.054-0.588$ & 0.123 & 0.263 \\
\hline III & $0.148-0.573$ & $0.344-2.328$ & 0.411 & 0.925 \\
\hline IV & 0.732 & $0.896-3.286$ & 0.732 & 2.163 \\
\hline
\end{tabular}

Sumber : Hasil Penelitian (2016)

\section{c. Fekunditas}

Sampel ikan Swanggi untuk fekunditas sebanyak 16 ekor. Perhitungan sampel fekunditas selama penelitian dilakukan pada ikan yang memiliki TKG III dan IV dengan kisaran panjang 140 - 206 mm dan kisaran berat 38,7 - 106 gram. Fekunditas tertinggi ikan Swanggi adalah 245.303 butir pada panjang $198 \mathrm{~mm}$ dan berat tubuh 125,7 gram. Sedangkan fekunditas terendah sebanyak 123.500 butir, terdapat pada ikan Swanggi berukuran 190 mm dan berat tubuh 86,5 gram. Nilai koefisien korelasi hubungan antara fekunditas dengan panjang dan fekunditas dengan berat adalah sebesar 0,0798 dan 0,2462. Nilai korelasi tersebut menggunakan selang kepercayaan $95 \%$. Nilai koefisien korelasi menunjukkan bahwa hubungan panjang ikan Swanggi dengan fekunditas memiliki nilai koefisien korelasi (r) 0,0798 menunjukkan korelasi lemah. Hubungan berat dengan fekunditas ikan Swanggi memiliki nilai koefisien korelasi (r) 0,2462 menunjukkan korelasi lemah.

\section{d. Diameter Telur Ikan Swanggi}

Sampel ikan Swanggi untuk diameter telur yaitu berjumlah 12 ikan berdasarkan tingkat kematangan gonad yang berbeda dengan pengambilan acak. Hasil pengamatan diameter telur ikan Swanggi tersaji pada tabel 3. Tabel 3. Hasil Pengamatan Diameter Telur ikan Swanggi Selama Penelitian

\begin{tabular}{ccccc}
\hline No. & Tingkat Kematangan Gonad & \multicolumn{2}{c}{ Rata-rata diameter telur ikan Swanggi } \\
& (TKG) & Minggu ke 1 & Minggu ke 2 & Minggu ke 3 \\
\hline 1 & I & 0,022 & 0,024 & 0,025 \\
2 & II & 0,044 & 0,045 & 0,046 \\
3 & III & 0,30 & 0,28 & 0,27 \\
4 & IV & 0,34 & 0,31 & 0,32 \\
\hline
\end{tabular}

Sumber : Hasil Penelitian (2016)

Berdasarkan hasil pada tabel dan gambar diatas, diperoleh bahwa diameter telur ikan selama penelitian memiliki rata-rata diameter telur dengan TKG I sebesar 0,02; TKG II sebesar 0,04; TKG III sebesar 0,28 dan TKG IV sebesar 0.32. Data tersebut menunjukkan perbedaan ukuran diameter telur berdasarkan tingkat kematangan yang berbeda dengan diameter telur semakin tinggi tingkat kematangan gonad, maka semakin besar ukuran dimater telur ikan dan semakin rendah tingkat kematangan gonad, maka semakin kecil ukuran diameter telur ikan. 


\section{PEMBAHASAN \\ Aapek Pertumbuhan}

Hasil perhitungan panjang berat dengan menggunakan analisis regresi linier dengan selang kepercayaan $95 \%$ didapatkan nilai a sebesar 0,00045 dan nilai b sebesar 2,30701, sehingga didapatkan persamaan $\mathrm{W}=$ $0,00045 \mathrm{~L}^{2,30701}$. Hal ini menunjukkan bahwa pertumbuhan ikan Swanggi bersifat allometrik negatif. Menurut Effendie (2002), apabila b kurang dari 3 menunjukkan keadaan ikan yang kurus dimana pertambahan panjangnya lebih cepat dari pertambahan beratnya. Menurut penelitian yang dilakukan Awong et al., (2011), pada ikan Swanggi pola pertumbuhan allometrik negatif diduga dipengaruhi oleh tekanan penangkapan. Menurut Iswara (2014), faktor yang dapat mempengaruhi perbedaan pertumbuhan panjang dan berat antara lain temperatur, salinitas, faktor ekologi, makanan (kuantitas dan kualitas) dan faktor lain seperti jenis kelamin, umur, waktu, dan area penangkapan.

Faktor kondisi adalah suatu keadaan yang menyatakan kemontokan ikan (Effendie, 2002). Nilai faktor kondisi ikan Swanggi selama penelitian adalah 1,106. Keadaan tersebut menunjukkan bahwa ikan Swanggi memiliki tubuh kurus. Menurut Effendie (2002), nilai K yang berkisar antara 1 - 3 menunjukkan bahwa badan ikan tersebut berbentuk kurang pipih dan masih berada pada batas ambang kondisi yang baik.

Ukuran pertama kali tertangkap ( $\mathrm{Lc}_{50} \%$ ) dihitung dengan tujuan agar dapat dijadikan dasar dalam pengaturan ukuran jaring yang digunakan demi menjaga kelestarian sumberdaya ikan Swanggi. Ukuran pertama kali tertangkap ( $\mathrm{Lc}_{50 \%}$ ) ikan Swanggi adalah $152 \mathrm{~mm}$. Berdasarkan hasil perhitungan $\mathrm{L}_{\infty}$ didapatkan nilai sebesar $336,84 \mathrm{~mm}$ dan nilai dari $1 / 2 \mathrm{~L}_{\infty}$ adalah $168,42 \mathrm{~mm}$ berarti bahwa ukuran ikan yang tertangkap masih kecil dan belum layak ditangkap, karena nilai $\mathrm{Lc}_{50 \%}<1 / 2 \mathrm{~L}_{\infty}$. Nilai $\mathrm{Lc}_{50 \%}$ dapat digunakan untuk menentukan faktor seleksi alat tangkap jaring Arad. Alat tangkap jaring Arad yang menjadi sampel saat penelitian memiliki mesh size pada bagian kantong sebesar 1 inchi $(25,4 \mathrm{~mm})$.

Ukuran pertama kali matang gonad penting untuk diketahui sebagai salah satu usaha dalam pengelolaan sumberdaya ikan. Ukuran pertama kali matang gonad $\left(\mathrm{Lm}_{50 \%}\right)$ ikan Swanggi adalah $153 \mathrm{~mm}$. Untuk mengetahui kondisi ikan pertama kali tertangkap apakah telah matang gonad atau belum, maka perlu dilakukan perbandingan antara nilai panjang pertama kali tertangkap ( $\left.\mathrm{Lc}_{50 \%}\right)$ dengan panjang pertama kali matang gonad ( $\left.\mathrm{Lm}_{50 \%}\right)$. Nilai $\mathrm{Lc}_{50 \%}(152 \mathrm{~mm})<\mathrm{Lm}_{50 \%}(153 \mathrm{~mm})$. Hal ini dapat diduga bahwa ikan yang tertangkap sebagian besar dalam kondisi belum matang gonad, sehingga kurang memberikan kesempatan ikan untuk memijah pertama kalinya dan dapat mengurangi populasi. Hal ini dikhawatirkan akan menyebabkan recruitment overfishing.

\section{Aspek Reproduksi}

Tingkat kematangan gonad dapat memberikan pengetahuan mengenai kondisi kematangan gonad pada ikan, apakah ikan tersebut dalam kondisi tidak matang, hampir matang, matang, reproduksi, salin maupun istirahat melalui ciri-ciri gonad akan diperoleh keterangan bilamana ikan itu memijah, baru memijah atau sudah selesai memijah (Saputra, 2009).

Jumlah gonad ikan Swanggi yang diamati secara morfologi selama bulan Maret dan April 2016 sebanyak 100 ekor. Jumlah sampel ikan Swanggi jantan 42 ekor dan betina 58 ekor. Sebagian besar ikan Swanggi jantan maupun betina yang diteliti berada pada fase yang belum matang gonad yaitu sebesar $79 \%$ dan $72 \%$, sedangkan yang telah matang gonad hanya sebesar $26 \%$ dan $28 \%$. Menurut Premalatha (1997) dalam Ballerena (2012), persentase ikan Swanggi betina dengan jantan yang telah matang gonad berbeda-beda setiap bulannya. Ikan Swanggi diduga memijah sepanjang tahun sesuai dengan yang dikemukan oleh Effendie (2002), bahwa ikan yang mempunyai musim pemijahan sepanjang tahun akan memiliki komposisi tingkat kematangan gonad dengan persentase yang tidak sama setiap pengambilan contoh.

Indeks kematangan gonad dihitung untuk mengetahui tingkat kematangan gonad berdasarkan berat gonad. Dari hasil yang didapat bahwa nilai IKG terendah pada ikan Swanggi jantan sebesar $0,018 \%$ dan nilai IKG tertinggi sebesar 0,732 \%. Sedangkan nilai IKG terendah pada ikan Swanggi betina sebesar 0,034 \% dan nilai tertinggi sebesar 3,286 \%. Menurut Effendie (2002), Gonado Somatic Index (GSI) akan semakin meningkat nilainya dan akan mencapai batas maksimum pada saat akan terjadi pemijahan. Dilihat dari rumus perhitungan IKG, bahwa nilai IKG berbanding lurus dengan nilai berat gonad. Artinya jika semakin besar nilai berat gonad maka nilai IKG juga akan semakin besar. Menurut Asyari dan Fatah (2011), ikan yang mempunyai nilai indeks kematangan gonad lebih kecil dari $20 \%$ adalah kelompok ikan yang memijah lebih dari sekali setiap tahunnya sehingga dapat diasumsikan bahwa ikan Swanggi memijah sepanjang tahun karena nilai indeks kematangan gonad lebih kecil dari $20 \%$.

Fekunditas merupakan ukuran penilaian potensi produksi ikan yaitu jumlah telur matang yang terdapat didalam ovari ikan betina. Ada 16 ekor ikan Swanggi yang digunakan untuk dihitung fekunditasnya. Fekunditas tertinggi ikan Swanggi adalah 245.303 butir dan terendah sebanyak 123.500 butir. Berdasarkan hasil penelitian yang dilakukan oleh Kirana et al., (2014), fekunditas terkecil adalah sebesar 127.928 butir dengan panjang tubuh $173 \mathrm{~mm}$ dan berat tubuh 69,5 gram. Sedangkan fekunditas terbesar adalah sebesar 227.571 butir dengan panjang tubuh $211 \mathrm{~mm}$ dan berat tubuh 132,4 gram. Besar kecilnya fekunditas dipengaruhi oleh makanan, ukuran ikan, dan kondisi lingkungan. Dari kedua hasil penelitian tersebut dapat dikatakan bahwa fekunditas ikan Swanggi memang berada pada kisaran hingga sekitar 250.000. Menurut Harianti (2013), jumlah telur yang dihasilkan oleh ikan akan meningkat sejalan dengan semakin besarnya gonad. Nilai koefisien korelasi menunjukkan bahwa 
hubungan panjang ikan Swanggi dengan fekunditas memiliki nilai koefisien korelasi (r) 0,0798 menunjukkan korelasi lemah. Hubungan berat dengan fekunditas ikan Swanggi memiliki nilai koefisien korelasi (r) 0,2462 menunjukkan korelasi lemah.

Ikan Swanggi memiliki rata-rata diameter telur untuk TKG I sebesar 0,02; TKG II sebesar 0,04; TKG III sebesar 0,28 dan TKG IV sebesar 0.32. Dari hasil tersebut menunjukkan perbedaan ukuran diameter telur berdasarkan tingkat kematangan yang berbeda. Semakin tinggi tingkat kematangan gonad, maka semakin besar ukuran dimater telur ikan dan sebaliknya semakin rendah tingkat kematangan gonad, maka semakin kecil ukuran diameter telur ikan. Menurut Harianti (2013), hubungan diameter telur dengan TKG, memperlihatkan bahwa semakin besar TKG maka semakin besar diameter telur yang didapatkan atau penyebaran diameter telur semakin besar. Hal ini menunjukkan bahwa semakin berkembang gonad ikan, telur yang berkembang di dalamnya semakin besar garis tengahnya.

\section{Upaya Pengelolaan Perikanan}

Berdasarkan hasil penelitian diperlukan pengelolaan sebagai upaya untuk mencegah overfishing dan terganggunya recruitmen dari ikan tersebut. Mesh size kantong jaring Arad yang digunakan yaitu 25,4 $\mathrm{mm}$ atau 1 inchi dengan nilai $\mathrm{Lc}_{50 \%}(152 \mathrm{~mm})<\mathrm{Lm}_{50 \%}(153 \mathrm{~mm})$. Hal ini dapat diduga bahwa ikan yang tertangkap sebagian besar dalam kondisi belum matang gonad, sehingga kurang memberikan kesempatan ikan untuk memijah pertama kalinya dan dapat mengurangi populasi.Alternatif upaya pengelolaan yang dapat diterapkan di PPP Tawang adalah membatasi ukuran mesh size alat tangkap dengan mengunakan alat tangkap ramah lingkungan, kemudian alternatif pengelolaan berikutnya adalah penentuan ukuran ikan yang boleh ditangkap dan antisipasi musim paceklik dengan diversifikasi usaha perikanan karena penangkapan ikan merupakan usaha yang tergolong tidak menentu, musim dan cuaca serta faktor lain terkadang menjadi kendala sehingga para nelayan tidak bisa sepenuhnya mengandalkan usaha penangkapan ikan itu untuk memenuhi kebutuhan sehari- hari.

\section{KESIMPULAN}

Berdasarkan hasil penelitian yang telah dilakukan dapat diambil kesimpulan sebagai berikut :

1. Aspek biologi ikan Swanggi dengan kisaran panjang 105-126 mm dan berat 22-205,2 gram; Pertumbuhan bersifat allometrik negatif dan nilai faktor kondisi (Kn) adalah 1,106; Ikan Swanggi jantan maupun betina sebagian besar belum matang gonad; Tingkat Kematangan Gonad (TKG) yang semakin tinggi akan diikuti dengan tingginya nilai Indeks Kematangan Gonad (IKG) dan diameter telur juga semakin besar; Fekunditas tertinggi adalah 245303 butir; Nilai koefisien korelasi hubungan panjang dan berat ikan Swanggi dengan fekunditas menunjukkan korelasi lemah.

2. Alternatif upaya pengelolaan penangkapan ikan Swanggi di PPP Tawang adalah membatasi ukuran mesh size alat tangkap dengan mengunakan alat tangkap ramah lingkungan, kemudian alternatif pengelolaan berikutnya adalah penentuan ukuran ikan yang boleh ditangkap dan antisipasi musim paceklik dengan diversifikasi usaha perikanan.

\section{UCAPAN TERIMA KASIH}

Penulis mengucapkan terima kasih kepada Ibu Dra. Niniek Widyorini, MS; Bapak Dr. Ir. Bambang Sulardiono,M.Si; Ibu Ir. Siti Rudiyanti, M.Si; dan Ibu Churun Ain, S.Pi, M.Si selaku tim penguji yang telah memberikan arahan, bimbingan, serta kritik dan saran dalam penyusunan jurnal ini.

\section{DAFTAR PUSTAKA}

Asyari dan K. Fatah. 2011. Kebiasaan Makan dan Biologi Reproduksi Ikan Motan (Thynnichthys polylepis) di Waduk Kotopanjang, Riau. Balai Riset Perikanan Perairan Umum, Mariana-Palembang. $8 \mathrm{hlm}$.

Assiddiq, Z. Shaim. Hafidha. Febrianawati. Dian. 2011. Laporan Praktikum Mikroteknik dan Teknik Laboratorium Mikrometri. FMIPA UNY. Yogyakarta.

Awong H., S. Ibrahim, K. Somo, M. A. Ambak. 2011. Observation on Weight- Length Relationship of Priacanth us tayenus (Ricardson, 1846) Species in Darvel Bay, Sabah, Malaysia. Word Journal of Fish and Marine Sciences. 3 (3) : 239-242.

Ballerena, C. P. 2012. Pola Reproduksi Ikan Swanggi (Priacanthus tayenus, Richardson 1846) Yang Didaratkan di PPP Labuan Banten. [Skripsi]. Manajemen Sumberdaya Perairan. Institut Pertanian Bogor. Bogor.

Diana, E. 2007. Tingkat Kematangan Gonad Ikan Wader (Rasbora argyrotaenia) di Sekitar Mata Air Ponggok Klaten Jawa Tengah. [Skripsi]. Universitas Sebelas Maret Surakarta. Universitas Sebelas Maret Surakarta. Journal of Biological Diversity Vol. 5 No. $2.25 \mathrm{hlm}$. 
Effendie, M. I. 2002. Biologi Perikanan. Yayasan Pustaka Nusantara. Yogjakarta. 113 hlm.

Harianti. 2013. Fekunditas dan Diameter Telur Ikan Gabus (Channa striata,1793) di Danau Tempe, Kabupaten Wajo. Jurnal Saintek Perikanan. Vol. 8, No. 2, Halaman 18-24.

Iswara, K. W. 2014. Analisis Aspek Biologi Ikan Kuniran (Upeneus spp) Berdasarkan Jarak Operasi Penangkapan Alat Tangkap Cantrang di Perairan Kabupaten Pemalang. [Skripsi]. Universitas Diponegoro. Management of Aquatic Resources Journal Vol. 3, No. 4, 2014. 85 hlm.

Kirana, G.A, S.W. Saputra, Abdul Ghofar. 2014. Beberapa Aspek Biologi Ikan Swanggi (Priacanthus tayanus) Berdasarkan Hasil Tangkapan Yang Didaratkan Di PPP Morodemak. Vol. 3, No. 3, Tahun 2014, Halaman 144-152.

Prayudha, A.Y, S.W. Saputra, A.Solichin. 2014. Aspek Biologi Udang Caridea (Leptocarpus potamiscus, Kemp 1917) di Perairan Cilacap, Jawa Tengah. Universitas Diponegoro. Diponegoro Journal Of Maquares Vol. 3, No. 2, Tahun 2014, Halaman 27-35.

Rahman, D.R,I. Triarso, dan Asriyanto. 2013. Analisis Bioekonomi Ikan Pelagis pada Usaha Perikanan Tangkap di Pelabuhan Perikanan Pantai Tawang Kabupaten Kendal. Universitas Diponegoro. Journal of Fisheries Resources Utilization Management and Technology Vol. 2, No. 1, Tahun 2013, Hlm 1-10.

Saputra, S.W. 2009. Dinamika Populasi Berbasis Riset. Universitas Diponegoro. Semarang.

Simanjuntak, R. J. 2010. Keterkaitan Laju Eksploitasi dengan Pertumbuhan dan Reproduksi Ikan Petek Leiognathus equulu (Forsskal,1775) Famili Leiognathidae. Departemen Sumberdaya Perairan. Fakultas Perikanan dan Ilmu Kelautan. Institut Pertanian Bogor. Bogor. 